\title{
Magic and Antimagic Decomposition of Amalgamation of Cycles
}

\section{Sigit Pancahayani ${ }^{1, *}$ Annisa Rahmita Soemarsono ${ }^{2}$ Dieky Adzkiya ${ }^{3}$ Musyarofah $^{4}$}

\author{
${ }^{1}$ Department of Statistics, Institut Teknologi Kalimantan, Balikpapan, Indonesia \\ ${ }^{2}$ Department of Mathematics, Institut Teknologi Kalimantan, Balikpapan, Indonesia \\ ${ }^{3}$ Department of Mathematics, Institut Teknologi Sepuluh Nopember, Surabaya, Indonesia \\ ${ }^{4}$ Department of Physics, Institut Teknologi Kalimantan, Balikpapan, Indonesia \\ ${ }^{*}$ Corresponding author. Email: spancahayani@lecturer.itk.ac.id
}

\begin{abstract}
Consider $G=(V, E)$ as a finite, simple, connected graph with vertex set $V$ and edge set $E$. $G$ is said to be a decomposable graph if there exists a collection of subgraphs of $G$, say $\mathcal{H}=\left\{H_{i} \mid 1 \leq i \leq n\right\}$ such that for every $i \neq j, H_{i}$ is isomorphic to $H_{j}, \cup_{i=1}^{n} H_{i}=G$ and should satisfy that $E\left(H_{i}\right) \cap E\left(H_{j}\right)=\varnothing$ if $i \neq j$. Let $f: V(G) \cup E(G) \rightarrow\{1,2, \ldots,|V(G)|+$ $|E(G)|\}$ be a bijection mapping such that every subgraph in $\mathcal{H}$ has the same total of valuation $w\left(H_{i}\right)=$ $\sum(f(v)+f(e))=k$ for $v \in V\left(H_{i}\right)$ and $e \in E\left(H_{i}\right)$. In this paper, $k$ is called a magic constant. If every subgraph $H_{i} \cong$ $H$ and using this labelling results $w\left(H_{i}\right)=k$ for all $i$, then $G$ admits $H$-magic decomposition. Otherwise, if the total values among all subgraphs are different, then $G$ admits $H$-antimagic decomposition. In this research, a graph derived from amalgamating some cycles in a terminal vertex is the object to be investigated to find its property regarding magic decomposition. Furthermore, we find that the vertex amalgamation of some identical cycles admits both magic and antimagic decomposition, which depends on its order.
\end{abstract}

Keywords: Amalgamation, Magic, Antimagic, Decomposition, Cycle.

\section{INTRODUCTION}

In an organization, some problems may arise and sometimes need a formulation to find the best solution. This formulation uses mathematical notation and modeling. A problem that arises in an institution, such as task assignment for employees, frequently needs extra consideration since the unbalance workload among the employee may arise. Regarding this issue, some researchers had applied a method, for example, Linear Programming using Hungarian Method, to solve the workload problem $[1,2,3]$.

Another method studied in graph theory, magic decomposition, can also be implemented to the task assignment in a company. Using this method, initially, the workflow in this company needs to be modeled as a graph. Let it has some divisions, and each division consists of the same number of employees and their assignments. People in this division are denoted by vertex, and the assignments are illustrated as edges. The objective is to find the most proportional arrangement such that every division has the same workload.

In order to implement this concept, we use graph theory notation as follows. Consider $G=(V, E)$ as a finite, simple, connected graph with vertex set $V$ and edge set $E . G$ is said to be a decomposable graph if there exists a collection of subgraphs of $G$, say $\mathcal{H}=\left\{H_{i} \mid 1 \leq i \leq n\right\}$ such that for every $i \neq j, H_{i}$ is isomorphic to $H_{j}$, $\bigcup_{i=1}^{n} H_{i}=G$ and should satisfy that $E\left(H_{i}\right) \cap E\left(H_{j}\right)=\varnothing$ if $i \neq j$.

Let $f: V(G) \cup E(G) \rightarrow\{1,2, \ldots,|V(G)|+|E(G)|\}$ be a bijection mapping such that every subgraph in $\mathcal{H}$ has the same total of valuation, denoted by $\mathrm{w}$, that is for $v \in$ $V\left(H_{-} i\right)$ and $e \in E(G)$ altogether produce $w\left(H_{i}\right)=$ $\sum(f(v)+f(e))=k$. In this paper, we said k as a magic constant. If every subgraph $H_{i} \cong H$ of $G$ admits such labeling, then $G$ admits $H$-magic decomposition. Otherwise, if the total value among all subgraphs is different, then $\mathrm{G}$ admits $H$-antimagic decomposition. Furthermore, if $f(V(G)=\{1,2, \ldots,|V(G)|\}$, then the 
labeling is called super. The following results provide some results in this area. Subbiah et al. in [4] provide a characterization of 2-factor-edge-super magic decomposable graphs. Moreover, Hendy et al. in [5] had investigated a sufficient condition of $H$-super magic decompositions of the lexicographic product of cycles and complete graphs. On the other hand, Inayah et al. in [6] studied magic and antimagic decomposition for complete graphs, and Hendy et al. in [7] explained how to decompose antimagically toroidal grids and triangulations. Specifically, Xiong et al. in [8] worked and observed the amalgamation of wheels, fans, and flower graphs.

\section{MAIN RESULT}

This research deals with the magic and antimagic decomposition of vertex amalgamation of cycles. Let Amal $\left\{C_{n}\right\}_{t}$ be an amalgamation of $t$ number of cycles of order $n$ in $C=\left\{C_{i} \mid 1 \leq i \leq n\right\}$ which is constructed by joining all $C_{i}$ in a vertex $v_{0}$ called terminal. In order to find the desired decomposition, initially, we define the vertices and edges label in $\mathrm{Amal}\left\{\mathrm{C}_{n}\right\}_{t}$ as follows [9]:

For $i=1,2, \ldots, t$, each cycle $C_{n}$ consist of $V\left(C_{n}\right)=$ $\left\{v_{0}, v_{1}^{i}, v_{2}^{i}, \ldots, v_{n-1}^{i}\right\}$ and $E\left(C_{n}\right)=\left\{e_{j}=v_{j-1}^{i} v_{j}^{i}, e_{n}=\right.$ $\left.v_{n-1}^{i} v_{0} \mid j=1,2, \ldots, n-1\right\}$.

From this definition, we have $\left|V\left(\operatorname{Amal}\left\{C_{n}\right\}_{t}\right)\right|=$ $(n-1) t+1$ and $\left|E\left(\operatorname{Amal}\left\{C_{n}\right\}_{t}\right)\right|=n t$. Therefore, we will have $2 n t-t+1$ natural number to label the graph such that it can be decomposed to be magic or anti-magic.

Let $A$ be a finite set of natural numbers. The sum of all elements in $X$ is called the sumset of $A$ in [6] and denoted by

$\sum A=\sum_{a \in A} a$.

The following lemma provides a property regarding how to set the labels into an appropriate arrangement.

\section{Lemma 1}

Let $t$ be an odd natural number and $A=\{i \mid 1 \leq i \leq$ $2 t\}$ be a set of natural numbers. Define $\mathcal{A}=\left\{A_{j} \subset\right.$ $A \mid 1 \leq j \leq t\}$ be a collection of $t$ number disjoint subsets of $A$, which consist of two elements. Then there is an arrangement such that the sumset of each subset $A_{j}$ forms an arithmetic progression that differs 1 .

\section{Proof}

First of all, we need to divide the index $j$ into even and odd. For $j$ odd, set $A_{j_{o d d}}=\left\{\left\lceil\frac{j}{2}\right\rceil,\left\lceil\frac{j}{2}\right\rceil+\left\lfloor\frac{3 t}{2}\right\rfloor\right\}$ and for $j$ even, set $A_{j_{\text {even }}}=\left\{\frac{j}{2}+\left\lceil\frac{t}{2}\right\rceil, \frac{j}{2}+t\right\}$. Therefore,

$\sum A_{j_{\text {even }}}-\sum A_{j_{\text {odd }}}=\left(\frac{j}{2}+\left\lceil\frac{t}{2}\right\rceil+\frac{j}{2}+t\right)-\left(\left\lceil\frac{j}{2}\right\rceil+\left\lceil\frac{j}{2}\right\rceil+\right.$
$\left.\left\lfloor\frac{3 t}{2}\right\rfloor\right)=j+\frac{3 t+1}{2}-j+1-\frac{3 t+1}{2}=1$.
Now, let $v=\left|V\left(\operatorname{Amal}\left\{C_{n}\right\}_{t}\right)\right|=(n-1) t+1$ and $e=\left|E\left(\operatorname{Amal}\left\{C_{n}\right\}_{t}\right)\right|=n t$. Also for each $n$, define the vertex set $V\left(C_{n}^{i}\right)=\left\{v_{0}, v_{1}^{i}, v_{2}^{i}, v_{3}^{i}, \ldots, v_{n_{i}-1}^{i}\right\}$ and its edge set as $E\left(C_{n}^{i}\right)=\left\{e_{1}^{i}, e_{2}^{i}, \ldots, e_{n}^{i}\right\}$.

\section{Theorem 1}

Let $n \geq 3$ and $t$ are natural numbers. Graph Amal $\left\{C_{n}\right\}_{t}$ can be decomposed into $t$ number of $C_{n}$ as follow:

i. $\quad$ if $t$ is an odd number, $\operatorname{Amal}\left\{C_{n}\right\}_{t}$ admits a super magic $C_{n}$ decomposition with magic constant $k=n(2 n t-t+2)-\frac{1}{2}(t+1)$

ii. If $t$ is an even number $\operatorname{Amal}\left\{C_{n}\right\}_{t}$ admits an (a,d)-antimagic $C_{n}$ decomposition with $a=$ $2 n^{2} t-n t+2 n-\frac{3 t}{2}+1$ and $d=1$.

\section{Proof}

i. First of all, we need to set vertex labeling and edge labeling as follow:

$f: V\left(\operatorname{Amal}\left\{C_{n}\right\}_{t}\right) \rightarrow\{1,2,3, \ldots, v\}$ such that

$f\left(v_{0}\right)=v$

$f\left(v_{j}^{i}\right)=i+(j-1) t$, for $i=1,2,3, \ldots, t$ and $j=$

$1,2,3, \ldots, n-2$

And $f\left(v_{j}^{i}\right)=(n-1) t+1-i$, for $j=n-1$.

Using (1), the total of vertex label of each $C_{n}^{i}$ is the sum of Equation (2), (3), and (4), that is

$$
\begin{aligned}
& f\left(v_{0}\right)+\sum_{j=1}^{n-2} f\left(v_{j}^{i}\right)+f\left(v_{n-1}^{i}\right) \\
& =(n-1) t+1+\sum_{j=1}^{n-2}(i+(j-1) t)+(n-1) t \\
& \quad+1-i \\
& =2(n t-t+1)-i+(n-2)\left(i-t+\frac{t(n-1)}{2}\right) \\
& =2 n t-2 t+2+\frac{t\left(n^{2}-5 n+6\right)}{2}+(n-3) i \\
& =\frac{1}{2}\left(n^{2} t-n t+2 t+4\right)+(n-3) i
\end{aligned}
$$

On the other hand, its edge labeling is based on the following assignment

$g: E\left(\operatorname{Amal}\left\{C_{n}\right\}_{t}\right) \rightarrow\{v+1, v+2, v+3, \ldots, v+e$

Using Lemma $1, g\left(e_{1}^{i}\right)$ and $g\left(e_{2}^{i}\right)$ are defined as follow:

$g\left(e_{1}^{i}\right)=\left\{\begin{aligned}\left\lceil\frac{i}{2}\right\rceil+v, & i \text { odd } \\ \frac{i}{2}+\left\lceil\frac{t}{2}\right\rceil+v, & i \text { even }\end{aligned}\right.$ 
$g\left(e_{2}^{i}\right)=\left\{\begin{array}{r}{\left[\frac{i}{2}\right\rfloor+\left\lfloor\frac{3 t}{2}\right\rfloor+v, i \text { odd }} \\ \frac{i}{2}+t+v, i \text { even }\end{array}\right.$

and

$g\left(e_{j}^{i}\right)=v+j t+1-i$ for $j=3,4,5, \ldots, n ; i=$ $1,2, \ldots, t$.

Adding up the Equation (6), (7), and (8), then the total of edge label for each $C_{n}^{i}$ when $i$ is odd results

$$
\begin{aligned}
g\left(e_{1}^{i}\right)+g\left(e_{2}^{i}\right)+\sum_{j=3}^{n} g\left(e_{j}^{i}\right) \\
=\left\lceil\frac{i}{2}\right\rceil+v+\left[\frac{i}{2}\right]+\left\lceil\frac{3 t}{2}\right\rfloor+v+\sum_{j=3}^{n}(v+j t+1-i) \\
=2 v+i+1+\frac{3 t-1}{2}+(n-2)(n t-t+2-i) \\
\quad+\frac{n t(n+1)}{2}-3 t \\
=2 n t-2 t+2+i+\frac{3 t-1}{2}+\cdots \\
\ldots+\frac{1}{2}\left(3 n^{2} t-5 n t+4 n-2 t-8\right)-(n-2) i \\
=\frac{1}{2}\left(4 n t-4 t+4+3 t-1+3 n^{2} t-5 n t+4 n\right) \\
-t-4-(n+3) i \\
=\frac{1}{2}\left(3 n^{2} t-n t-3 t+4 n-5\right)-(n-3) i
\end{aligned}
$$

Adding Equation (5) and (9) gives the magic constant $k=n(2 n t-t+2)-\frac{1}{2}(t+1)$.

Using the same procedure for $i$ as an even number, then the same constant magic is achieved.

Moreover, we can see from this labeling that the label $v$ is encountered $(t-1)$ times. So, the total label for each $C_{n}$ is

$$
\begin{aligned}
k= & \frac{1}{t}\left[(t-1) v+\sum_{i=1}^{v+e} i\right] \\
= & \frac{1}{t}\left[(t-1)[(n-1) t+1]+\sum_{i=1}^{2 n t-t+1} i\right] \\
= & \frac{1}{t}\left[\left(n t^{2}-n t-t^{2}+2 t-1\right)\right. \\
& \left.+\left(2 n^{2} t^{2}-2 n t^{2}+\frac{t^{2}}{2}+3 n t-\frac{3}{2} t+1\right)\right] \\
= & 2 n^{2} t-n t-\frac{t}{2}+2 n+\frac{1}{2} \\
= & n(2 n t-t+2)-\frac{1}{2}(t+1)
\end{aligned}
$$

Therefore, if $t$ is an odd number, $\operatorname{Amal}\left\{C_{n}\right\}_{t}$ admits a super magic $C_{n}$ decomposition with magic constant $k=n(2 n t-t+2)-\frac{1}{2}(t+1)$.

ii. Let $n$ be any natural number and $t$ is an even number. The term $\frac{1}{2}(t+1)$ in Equation (10) is not a natural number. So, there is no (super) $C_{n}$-magic decomposition in $\operatorname{Amal}\left\{C_{n}\right\}_{t}$ using the vertex and edge labeling as mentioned in part (i) of this proof. Since it applies vertex labeling in Equation (2) for $j=0$ and Equation (3) for $j=1,2, \ldots, n-1$ (without Equation (4)), so the total of vertex label of each $C_{n}^{i}$ is

$$
\begin{aligned}
& f\left(v_{0}\right)+\sum_{j=1}^{n-1} f\left(v_{j}^{i}\right) \\
& =(n-1) t+1+\sum_{j=1}^{n-1}(i+(j-1) t) \\
& =1+\frac{\left(n^{2}-n\right)}{2} t+(n-1) i
\end{aligned}
$$

And then, using edge labeling in Equation (6) and (7), we can see that for $i$ odd,

$$
g\left(e_{1}^{i}\right)+g\left(e_{2}^{i}\right)=i+1+2 v+\frac{3 t}{2},
$$

but for $i$ even,

$$
g\left(e_{1}^{i}\right)+g\left(e_{2}^{i}\right)=i+2 v+\frac{t}{2}
$$

which means that the total label of each $C_{n}^{i}$ are consecutive with different 1 .

On the other hand, its edge labeling is based on the Equation (6), (7), and (8). So, the total of edge label for each $C_{n}^{i}$, when $i$ is even, is

$$
\begin{aligned}
g & \left(e_{1}^{i}\right)+g\left(e_{2}^{i}\right)+\sum_{j=3}^{n} g\left(e_{j}^{i}\right) \\
= & \left\lceil\frac{i}{2}\right\rceil+v+\left\lceil\frac{i}{2}\right\rceil+\left\lfloor\frac{3 t}{2}\right\rfloor+v \\
& +\sum_{j=3}^{n}(v+j t+1-i) \\
= & i+1+2 v+\frac{3 t}{2}+\sum_{j=3}^{n}(v+j t+1-i) \\
= & \frac{1}{2}\left(4 n t-4 t+4+3 t+3 n^{2} t-5 n t\right. \\
& +4 n-2 t-8)-(n+3) i \\
= & \frac{1}{2}\left(3 n^{2} t-n t-3 t+4 n-4\right)-(n-3) i
\end{aligned}
$$

Choose $i=1$, then the sum of Equation (11) and (12) gives the smallest total label in $C_{n}^{i}$, that is

$a=1+\frac{\left(n^{2}-n\right)}{2} t+(n-1)$ 


$$
\begin{aligned}
& +\frac{1}{2}\left(3 n^{2} t-n t-3 t+4 n-4\right)-(n-3) \\
= & 2 n^{2} t-n t+2 n-\frac{3 t}{2}+1 .
\end{aligned}
$$

This proves that for $t$ even number, $\operatorname{Amal}\left\{C_{n}\right\}_{t}$ admits a super $(a, d)-C_{n}$-antimagic decomposition.

Figure 1 illustrates how to build an amalgamation of 5 copy of $C_{7}$ with notion of its vertices and edges. Moreover, Figure 2 shows the vertex and edge labeling, so it admits super $C_{5}$-magic decomposition with magic constant $k=467$.

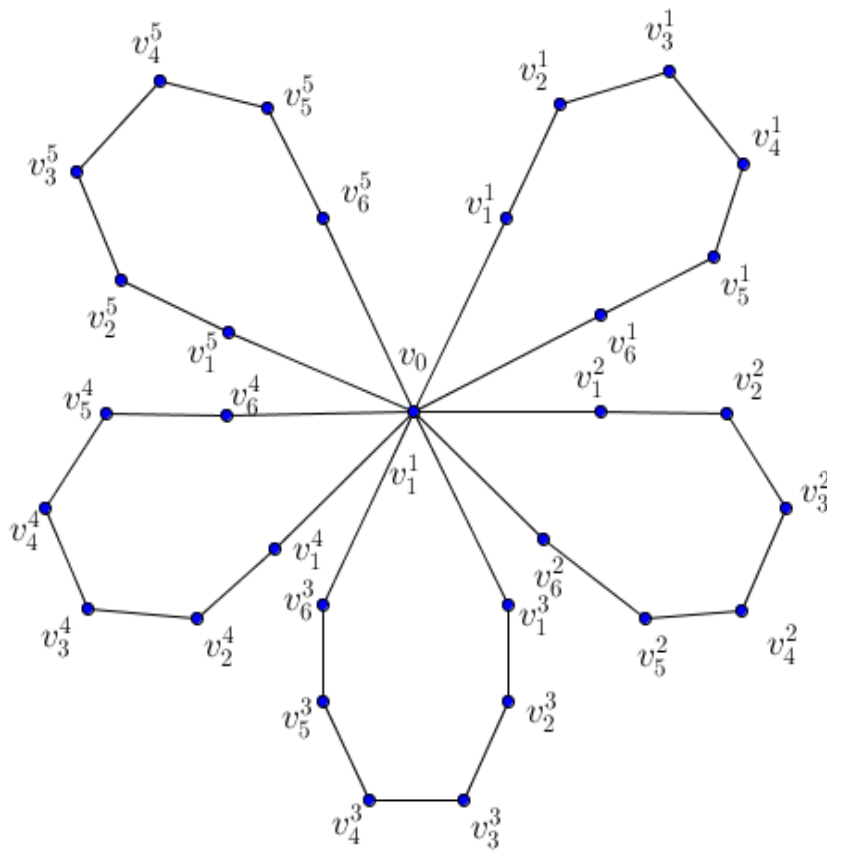

Figure 1 Amalgamation of 5 copy of identical cycles of order 7, $\operatorname{Amal}\left\{C_{7}\right\}_{5}$.

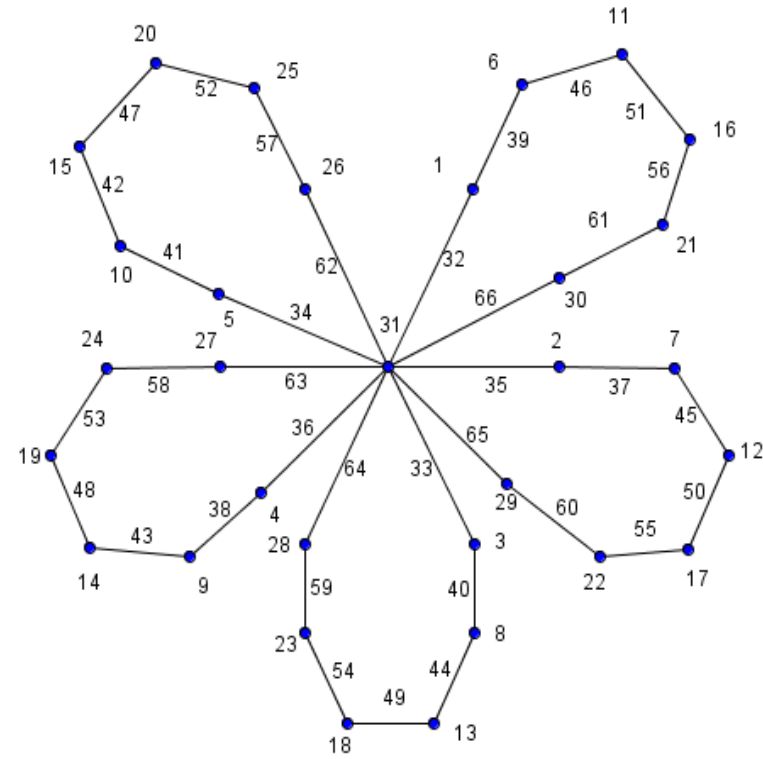

Figure 2 Vertex and edge labeling on $\operatorname{Amal}\left\{C_{7}\right\}_{5}$.
The following result shows that the magic constant can have many alternatives as stated in Corollary 1.

\section{Corollary 1}

The bound of the magic constant of $A \operatorname{mal}\left\{C_{n}\right\}_{t}$ with $n \geq 3$ and $t$ is an odd number such that it has a $C_{n}$-super magic decomposition is $2 n^{2} t-2 n t+\frac{t}{2}+3 n-\frac{1}{2} \leq$ $k \leq n(2 n t-t+2)-\frac{1}{2}(t+1)$.

\section{Proof.}

The lower bound of the magic constant can be achieved when the terminal vertex is assigned by label 1, while label $v$ is applied for its upper bound. Using similar vertex labeling and edge labeling from theorem 1 by changing the label of $v_{0}$ from $v$ to 1 , the following magic constant is for $f\left(v_{0}\right)=1$, while if $f\left(v_{0}\right)=v$ is already shown in the previous proof.

$$
\begin{aligned}
k & =\frac{1}{t}\left[(t-1)+\sum_{i=1}^{v+e} i\right] \\
& =\frac{1}{t}\left[(t-1)+\sum_{i=1}^{2 n t-t+1} i\right] \\
& =\frac{1}{t}[(t-1)+\cdots \\
& \left.\cdots+\left(2 n^{2} t^{2}-2 n t^{2}+\frac{t^{2}}{2}+3 n t-\frac{3}{2} t+1\right)\right] \\
& =\frac{1}{t}\left[2 n^{2} t^{2}-2 n t^{2}+\frac{t^{2}}{2}+3 n t-\frac{1}{2} t\right] \\
& =2 n^{2} t-2 n t+\frac{t}{2}+3 n-\frac{1}{2} \\
& =n(2 n t-t+2)-\frac{1}{2}(t+1)
\end{aligned}
$$

\section{CONCLUSION}

The amalgamation of $t$ copy of cycles is a graph that is obtained by joining some (identical) cycles in a terminal vertex, denoted by $\operatorname{Amal}\left\{C_{n}\right\}_{t}$. For any $n$ natural number and $t$ odd number, then $\operatorname{Amal}\left\{C_{n}\right\}_{t}$ admits a super $C_{n}$-magic decomposition, but for $t$ even number, it admits a super $C_{n}$-antimagic decomposition.

\section{AUTHOR'S CONTRIBUTION}

SP carried out the topic research, made a resume, drafted a manuscript, constructed conjectures and theorems, and provided proof of theorems. ARS contributed in drafting manuscript, constructed theorem and proved it. DA and $\mathrm{M}$ participated in designing this research, and helped to draft the manuscript. All authors read and approved the final manuscript. 


\section{ACKNOWLEDGMENTS}

The author would like to acknowledge the Directorate of Research and Community Service (LPPM) of Institut Teknologi Kalimantan for funding this research by DIPA ITK Grant No. 2159/IT10/PPM.05/2021.

\section{REFERENCES}

[1] S Rusdiana, R Oktavia, E Charlie, Application of Hungarian Method in Optimizing the Scheduling of Employee Assignment and Profit of Home Industry Production, in Journal of Research in Mathematics Trends and Technology (JoRMTT), Vol. 01, No. 01, Talenta Publisher, 2019, pp 24-33. DOI: https://doi.org/10.32734/jormtt.v1i1.754

[2] N P Akpan, U P Abraham, A Critique of the Hungarian Method of Solving Assignment Problem to the Alternate Method of Assignment Problem by Mansi, in: International Journal of Sciences: Basic and Applied Research (IJSBAR), Vol 29, No 1, 2016, ISRRA, pp 43-56

[3] D Priya, G Ramesh, The Hungarian Method for the Assignment Problem, with Generalized Interval Arithmetic and Its Application, in: Journal of Physics: Conference Series, Vol. 1377, 2019, IOP Science, pp 1-15. DOI: doi:10.1088/17426596/1377/1/012046

[4] S P Subbiah, J Pandimadevi, H-E- Super magic decomposition of graphs, in Electronic Journal of Graphs Theory and Application, Vo; 2., No. 2, 2014, pp 115-128.

DOI: http://dx.doi.org/10.5614/ejgta.2014.2.2.4

[5] Hendy, K A Sugeng, A N M Salman, N Ayunda, Another $\mathrm{H}$-Super magic decompositions of the lexicographic product of graphs, in: Indonesian Journal of Combinatorics, Vol. 2, No. 2, 2018, AIP Publishing LLC, pp 72-81. DOI: 10.19184/ijc.2018.2.2.2

[6] N Inayah, A Llado, J Moragas, Magic and antimagic $H$-decompositions, in: Discrete Mathematics, Vol. 312, 2012, Elsevier, pp 1367-1371. DOI: https://doi.org/10.1016/j.disc.2011.11.041

[7] Hendy, A N Mudholifah, K A Sugeng, M Baca, A Semanicova-Fenovcikova, On $H$-antimagic decomposition of toroidal grids and triangulations, in: AKCE International Journal of Graphs and Combinatorics, Vol. 17, No.3, 2020, Taylor and Francis, pp 761-770. DOI: https://doi.org/10.1016/j.akcej.2019.09.006

[8] Y. Xiong, H. Wang, M. Habib, M. A. Umar and B. R. Ali, Amalgamations and Cycle-Antimagicness, in: IEEE Access, vol. 7, 2019, pp. 147345-147349 DOI: 10.1109/ACCESS.2019.2936844.

[9] S Pancahayani, A Path-Super magic decomposition of the vertex amalgamation of some cycles, in Jurnal Matematika dan Pendidikan Matematika, Vol 2, No. 2, 2017, Universitas Pesantren Darul Ulum Jombang, pp 128-133. DOI: https://doi.org/10.26594/jmpm.v2i2.905 